\title{
Effect of hydraulic conductivity of unsaturated soil on the earth dam performance
}

\author{
Mohammed Fattah ${ }^{1, *}$, Mahmood Ahmed ${ }^{2}$ and Nawar $\mathrm{Ali}^{2}$ \\ ${ }^{1}$ Building and Construction Engineering Dept., University of Technology, Baghdad, Iraq \\ ${ }^{2}$ College of Engineering, University of Baghdad, Baghdad, Iraq
}

\begin{abstract}
In this paper, the finite element method is uzed to solve the governing equations of flow through earth dams. The computer program Geo-Slope is used in the analysis through its sub-program named SEEP/W. A case study is considered to be Al-Adhaim dam which consists of zoned embankment with a total length of $3.1 \mathrm{~km}$. The dam in its actual design is analyzed. Then, an attempt is made to study the seepage in unsaturated zone of the dam through studying the effect of several parameters including the effect of changing the unsaturated hydraulic conductivity with the degree of saturation of the core soil and changing of water level in the reservoir. A procedure is proposed to define the hydraulic conductivity function from the soil water characteristic curve which is measured by the filter paper method. Fitting methods are applied through the program SoilVision. A parametric study was carried out and different parameters were changed to study their effects on the behavior of partially saturated soil. The study reveals that the rate of flow is decreased by about $20-27 \%$ when the degree of saturation of the core material is decreased from $100 \%$ to $50 \%$ at water level $115.75 \mathrm{~m}$, while the exit gradient of flow is decreased by about $13-15 \%$. This decrease in flow rate becomes $13-15 \%$ and $8-9.5 \%$ when the reservoir water level is $131.5 \mathrm{~m}$ and $143.5 \mathrm{~m}$, respectively, while the exit gradient of flow is increased by about $23-29.5 \%$ and $29-29.5 \%$ when the reservoir water level is $131.5 \mathrm{~m}$ and $143.5 \mathrm{~m}$, respectively. When the state of soil changes from fully saturated $S=100 \%$ to partially saturated $S=90 \%$, a rapid increase in head gradient and pore water takes place at the embankment base for different water levels in the reservoir. This decrease plateaus out on further decrease in the degree of saturation.
\end{abstract}

\section{Introduction}

Seepage problems in geotechnical engineering have been generally solved by sketching flow nets. This method is based on the assumption that water flows only in the saturated zone. This method of solution is practical for simple steady state problems where the boundary of the flow region is clearly defined and the soil conditions are not too complex. However, many seepage problems of practical interest are complex, and a flow-net solution is not feasible. With the development of high-speed digital computers, numerical methods are increasingly used in solving seepage problems. Some of the first attempts at modeling seepage using the finite element method also considered water flow only in the saturated zone. In this "saturated-only" approach, the phreatic line was assumed to be the upper boundary of the flow region for unconfined flow problems. In order to obtain the location of the phreatic line, a trial and error procedure was used to search for a surface that has both zero water pressure along it and zero flow across it. For each trial, the location of the phreatic line was readjusted, and a new mesh is constructed. This method is tedious, and it is also based on the erroneous assumption that the phreatic line was the uppermost flow boundary.

Darcy's law was originally derived for saturated soil, but can equally be applied to the flow of water through an unsaturated soil. The only difference is that for flow through an unsaturated soil, the coefficient of permeability is no longer a constant but is a function of the matric suction of the soil.

Lam et al. (1987) presented the development of a transient finite element seepage model using an approach consistent with that used by geotechnical engineers. The concepts pertinent to the understanding of unsaturated flow were reviewed. The general governing differential equation for transient seepage was derived and the finite element solution to the equation was presented. Three iterative techniques, including the secant method, have also been incorporated to ensure convergence for highly nonlinear flow systems. Changing boundary conditions during a transient process was accommodated by a prescribed step function.

Thieu et al. (2001) presented the application of general-purpose partial differential equation solvers associated soil property functions to the analysis of

Corresponding author: myf 1968@yahoo.com 
saturated-unsaturated seepage problem. The soil material was assumed to be silt and isotropic with respect to the coefficient of permeability. Experimental data showing the coefficient of permeability versus matric suction, and the volumetric water content versus matric suction were obtained from Ho (1979). The saturated coefficient of permeability was $2.5 \times 10^{-7} \mathrm{~m} / \mathrm{sec}$ and the saturated volumetric water content was 0.381 . The finite element computer program PDEase2D was used for the analysis of the steady-state seepage problem. A maximum error of $0.1 \%$ was specified. The results of the total head distribution were presented in the form of pore-water pressure distribution and flow vectors under steady state seepage. The position of the total head contours and phreatic lines are the same for all permeability functions.

Modelling one-dimensional flow process in unsaturated soils is usually based on the numerical solutions of the Richards's equation which may be expressed in water content form, pressure or mixed form. Bouchemella et al. (2014) tried to test the accuracy of the results and the ability of the different forms of Richards's equation to describe the water flow in unsaturated soils. Implicit finite difference scheme was used in the numerical solution of the water content form and the pressure form of Richards's equation. The solution of the mixed form was obtained using the 1-D Hydrus software. The effect of texture and the initial moisture of the soil on the equation solutions were explored. The results showed a significant difference under some conditions. The choice of the empirical model to describe the hydraulic properties like retention curve and hydraulic conductivity may play an important role on the performance of each form, and can lead to remarkably different simulation results. The accuracy of the results was established by comparing numerical results to the semi-analytical solution of Philip and confronting them to the measured results.

In this study, the aim of experimental work is to define the soil water characteristic curve SWCC by measurement of the soil suction. Soil samples were collected from a site east of Baghdad. The physical properties of this soil were studied by conducting a series of tests in the laboratory, these include: specific gravity, Atterberg limits, grain size distribution by sieve analysis and hydrometer, compaction test and permeability test (falling head). The total and matric suction were measured by the filter paper method at different degrees of saturation. The unsaturated coefficient of permeability was then calculated. These parameters were implemented in the finite element analysis of a zoned earth dam.

\section{Experimental program}

A brown clayey soil was brought from a site east of Baghdad. Standard tests were performed to determine the physical properties of the soil. Details are given in Table 1. Grain size distribution of the soil used revealed $3.3 \%$ sand, $31.7 \%$ silt and $65 \%$ clay. The samples were subjected to testing program which included the following tests :
The specific gravity for the soil studied was determined according to ASTM D854-00.

The liquid and plastic limit tests were carried out on the soil passing sieve No. 40 according to ASTM D4318-00. The results are shown in Table 1. Wet sieving (by water), and hydrometer tests were carried out in accordance with ASTM-D422-02. The soil is classified as silty clay according to "ASTM" classification, designated as CL according to the Unified Soil Classification System, and the percentage of clay is summarized in Table 1. The compaction test was carried out on soil passing sieve No. 4 according to ASTMD698-00 in order to find the dry unit weight and optimum moisture content. The results are summarized in Table 1. Falling head permeability test was carried out on soil samples following the procedure described by Head and Epps (2011).

\subsection{Total and matric suction of soil measurement by filter paper method}

The filter paper method was used for soil suction measurements because of its advantages over other suction measurement devices. The method basically depends on the principle that at equilibrium, the suction value of the filter paper and the soil will be equal. After equilibrium is established between the filter paper and the soil, the water content of the filter paper disc is measured. Then, by using filter paper water content versus suction calibration curve, the corresponding suction value is found from the curve. This is the basic approach suggested by ASTM Standard Test Method for Measurement of Soil Potential (Suction) Using Filter Paper (ASTM D 5298). In other words, ASTM D 5298 employs a single calibration curve that has been used to infer both total and matric suction measurements.

\subsection{Description of the problem}

Al-Adhaim dam is an earth dam located at Al-Adhaim river north of Baghdad in Iraq. It consists of embankment of length $3.1 \mathrm{~km}$ from the helm of a major cross-river valley where it is $73.5 \mathrm{~m}$ high and go through or underneath spending and channel spillway. AlAdhaim dam consists of fill soil with sloping core. The initial architecture of the dam has been developed by Bennie and Partners Company. The soil of the foundation consists of sloping layers of sandstone and marl of uneven thickness (Al-Adhaim Dam Report, 1994).

Figure 1 shows section of the dam, which has a base level of about $70 \mathrm{~m}$ above the sea level summit dam, and the level at the top of dam was $146.5 \mathrm{~m}$ (Al-Adhaim Dam Report, 1994). Al-Adhaim dam is a filling dam consisting of three main zones: shell, core, and filters as shown in Figure 1. The thickness of this filling changes with the height of the dam where it is at greatest value at the base and gradually decreases with increase of the height. The height of the dam depends on the height of land, which varies from a few meters rival parties and up to about $70 \mathrm{~m}$ at the confluence with the metaphor of the 
river, and below is a brief description of the dimensions and slope of the dam:

The shell is composed of sand and gravel in general, the width at top is $12 \mathrm{~m}$, while the slope at the upstream is $1: 2.5$ and the downstream is $1: 2$.

The core consists of silty clay sliding towards the upstream of the dam with the slope 1:1.1 and 1:2. The form of core sections is chimney and the kind of slope and the thickness is $8 \mathrm{~m}$ at the elevation $143.5 \mathrm{~m}$ and this thickness gradually increases until it reaches $33 \mathrm{~m}$ at elevation $70 \mathrm{~m}$ and the thickness at any point of the core is $50 \%$ of the height of water at that point. This thickness is good and impedes water leakage. At elevation $70 \mathrm{~m}$, the core soil merges with the marl soil at the foundation that formed an impediment which prevents leakage of water under the dam (Al-Adhaim Dam Report, 1994). The drainage consists of vertical and horizontal filters. Bennie and Partners implemented that the vertical filter consists of two layers to protect the core, the thickness of the target layer with core is $2 \mathrm{~m}$ called filter $\mathrm{F}$ and the thickness of other layer is $2.5 \mathrm{~m}$ called filter $T$. The horizontal drainage consists of three layers filter F $0.3 \mathrm{~m}$, filter T $2.5 \mathrm{~m}$, and filter F $0.5 \mathrm{~m}$ target with foundation (Al-Adhaim Dam Report, 1994). The specified materials of Al-Adhaim dam are shown in Table 2.

In this paper, the soil from core material has been selected for study and has been subjected to a set of laboratory tests. The soil of core has the properties shown in Table 3, which were calculated from laboratory tests carried out on disturbed samples.

\subsection{Required relationships for unsaturated soils}

Before starting the analysis, there are some relationships required in dealing with partially saturated soil characteristics, which are:

\section{Suction versus degree of saturation}

Total and matric suction of the soil samples are measured by remolding the samples at different degrees of saturation $40 \%, 50 \%, 60 \%, 70 \%, 80 \%$, and $90 \%$ using the filter paper method.

\section{Volumetric water content $\boldsymbol{\theta}_{\mathrm{w}}$}

One of required input data in SEEP/W program is relationship between volumetric water content and pore water pressure. SEEP/W can estimate this relationship from input data such as, volumetric water content at saturated condition, $\theta_{\mathrm{s}}$, and coefficient of volume change, $m_{v}$, and from closed form solution of van Genuchten (1980), or closed form solution of Fredlund and Xing (1994).

The program Soil Vision is used here to find the soil water characteristic curve and estimated hydraulic conductivity. Mathematical representation of soil behavior is provided by Soil Vision with the fitting of mathematical equations to soil data. Standard equations used to represent soil behavior may be applied to laboratory data. Soil Vision helps application of mathematical equations to laboratory data for provided soil properties (User's Guide Manual of Soil Vision,
2001), including grain-size distribution, soil-water characteristic curve, permeability, compression (consolidation) and compaction, (User's Guide Manual of Soil Vision, 2001):

\section{Unsaturated hydraulic conductivity $k$}

After the volumetric water content function has been curve-fitted using the method proposed by Fredlund and Xing, (1994), then the hydraulic conductivity function can be predicted over the entire suction range i.e., from 0 to $10^{6} \mathrm{kPa}$, which removes the need to determine the residual water content, which is usually required for other predictive methods. The difficult task of measuring the unsaturated hydraulic conductivity function directly is often overcome by predicting the unsaturated hydraulic conductivity from either a measured or predicted volumetric water content function.

Additional input data in SEEP/W program is the relationship between hydraulic conductivity and pore water pressure. SEEP/W can estimate this relationship from input data such as saturated hydraulic conductivity and the volumetric water content relationship form solution of Fredlund and Xing (1994). For this reason, the Soil Vision program has been used

In this research, Soil Vision program has been used in order to find the properties of soil such as volumetric water content and unsaturated hydraulic conductivity. After determination of the relation between the volumetric water content and matric suction using the Fredlund and Xing model at every degree of saturation, a relationship between the hydraulic conductivity and matric suction can be estimated from Soil Vision program.

\section{Results of experiments:}

Figures 2 and 3 show the relationship between the total and matric suction and the degree of saturation, respectively. From these figures, it can be shown that the suction of the soil decreases with increase in the degree of saturation and the rate of decreasing in matric suction is not equal to the rate of increase of the degree of saturation.

From the program Soil Vision, and after inputting all the required properties of the soils used in this analysis, i.e., total unit weight, dry unit weight, liquid limit, plasticity index, void ratio, porosity, matric suction value, degree of saturation, and grain size distribution, the soil water characteristic curve is predicted (relation between the gravitation water content and the matric suction through applying fitting methods, such as the method proposed by Fredlund and Xing (1994) and van Genuchten (1980) for fitting the soil water characteristic curve as shown in Figure 4.

The most variable parameter in the Soil Vision program is saturated hydraulic conductivity and Fredlund and Xing fit of soil-water characteristic carve. Finally, the unsaturated hydraulic conductivity curve is predicted in Figure 5 for different degrees of saturation. 
From Figure 5, the hydraulic conductivity decreases when the degree of saturation decreases.

A steep permeability function indicates a rapid reduction in the water coefficient of permeability for a small increase in matric suction. In this case, the quantity of water flow into the unsaturated zone is considerably reduced since the coefficient of permeability decreases from $1 \times 10^{-7}$ to $1 \times 10^{-9} \mathrm{~m} / \mathrm{s}$. Additional input data in $\mathrm{SEEP} / \mathrm{W}$ program is the relationship between hydraulic conductivity and suction. SEEP/W can estimate this relationship from input data such as saturated hydraulic conductivity and the volumetric water content relationship from the solution of Fredlund and Xing (1994). This relation has been determined as shown in Figure 5.

\subsection{Seepage analysis of Al-Adhaim dam}

The steady state seepage through and under the earth dam is analyzed using the program SEEP/W. The finite element mesh used for the analysis is shown in Figure 6. The mesh includes higher-order eight-noded isoparametric elements for the entire body of the dam and its foundation. The number of elements is 1217 and the number of nodes is 3724 . The upstream boundary nodes are designated as head boundaries with total head equals to the water level in the reservoir $131.5 \mathrm{~m}$, and the downstream boundary nodes are designated with total head equal to $93 \mathrm{~m}$. The bottom nodes along the foundation are designated as a zero discharge (no flow). Default boundary conditions are assumed to be ordinary boundary (no flow) in Figure 6. The dam is assumed to be without filters in one case and with filters in the other.

\subsection{Results of finite element analysis and discussion}

At first, the soil that is selected in this research is used in the analysis of the dam as fully saturated soil by the program SEEP/W without and with the presence of filters.

Figure 7 shows the contours of total head and flow path the same water heads. The results of this analysis are summarized in Table 4.

The height of water $143.5 \mathrm{~m}$ represents the maximum design water level while the height $131.5 \mathrm{~m}$ represents the normal water level and the height 115.75 is the case where the reservoir is $50 \%$ filled with water. It can be noticed from Table 4 that the exit gradient is always less than 1.0 which means that the dam is safe in these conditions. Table 5 shows the results of analysis for the earth dam when using the soil of this research. Then, the dam is analyzed considering the core as partially saturated soil with different reservoir water levels 115.75 $\mathrm{m}, 131.5 \mathrm{~m}$, and $143.5 \mathrm{~m}$ with the same degree of saturation without and with the presence of filters. Later, each problem is re-analyzed considering different degrees of saturation. This means that for each case, the degree of saturation is changed from $40 \%, 50 \%, 60 \%$, $70 \%, 80 \%$, to $90 \%$ keeping the other parameters constant, and for each degree of saturation, the problem was re-analyzed with the same reservoir water level.

Figure 8 shows the seepage lines and velocity vectors through the dam considering that the core soil is the selected soil in this study for water level of $115.75 \mathrm{~m}$ in case of the dam with filters.

The phreatic line resulting from the saturatedunsaturated flow model is in close agreement with the empirical free surface from a conventional flow net construction. This observation supports the assumption that the empirical free surface is approximately equal to a phreatic line. However, water can flow across the phreatic line, as indicated by the nodal flow rate vectors. Water flow across the phreatic line into the unsaturated zone indicates that the phreatic line is not the uppermost flow line, as assumed in the flow net technique.

The water in the saturated and unsaturated zones then flows essentially parallel to the phreatic line in the central section of the dam. The water in the saturated zone then flows across the phreatic line into the unsaturated zone at the toe of the dam.

\subsection{Effect of height of water in the reservoir}

Two cases are considered to study the effect of height of water in the reservoir. The first case includes analysis of the dam without filters. Figures 9 and 10 show the relationship between the quantity of seepage at different heads of water when the dam is constructed without filters for degrees of saturation of the core soil of $40 \%$ and $50 \%$, respectively.

Figures 11 and 12 show the relationships between the height of water in the reservoir and exit gradient in the whole dam for conditions of degrees of saturation of $40 \%$ and $50 \%$, respectively. It can be noticed that the rate of flow is increased by about $45-84 \%$ when the height of water is increased from $151.75 \mathrm{~m}$ to $134.5 \mathrm{~m}$, while the exit gradient of flow is decreased by about $62.3-63.5 \%$.

Figures 13 and 14 show the relationships between the height of water in the reservoir and head gradient at nodes $\mathrm{A}$ and $\mathrm{B}$ shown in Figure 6 for conditions of degrees of saturation of $40 \% 50 \%$, respectively, while Figures 15 and 16 show the relationships between the height of water in the reservoir and the pore water pressure at nodes $\mathrm{A}$ and $\mathrm{B}$ for different degrees of saturation.

It can be concluded that the pore water pressure at node A which is located at elevation $93.0 \mathrm{~m}$ (embankment base) is increased by about $17-27 \%$ when the degree of saturation is decreased from $100 \%$ to $50 \%$ and $40 \%$, respectively. This increase becomes $28-39$ $\%$ at node $\mathrm{B}$ located at the center of core base. This means that the effect of unsaturated soil on the values of pore water pressure is clearer at the base of the dam core.

Table 6 summarizes the results of rate of flow, exit gradient of the earth dam at different degrees of saturation while Tables 7 and 8 present water pressure and head gradient at nodes $\mathrm{A}$ and $\mathrm{B}$ predicted at different 
degrees of saturation. It can be concluded that when the state of soil changes from fully saturated $S=100 \%$ to partially saturated $\mathrm{S}=90 \%$, a rapid decrease in head gradient and pore water takes place at node A and node B. This decrease plateau out on further decrease in the degree of saturation $\mathrm{S}$.

At the no-flow, or hydrostatic condition, suction head is distributed linearly because total head is a constant everywhere. The corresponding water content distribution is the soil-water characteristic curve. A minimum water content value occurs at the phreatic line, and the $100 \%$ saturation condition occurs at the water table. The air-entry head is the elevation above the water table at which desaturation commences.

Steady state flow causes a downward water flow. The negative pore water pressure increases from the static equilibrium condition. The hydraulic head profile starts with a positive value at ground surface and decreases to zero at the phreatic line. Therefore, water flows downward with a constant, negative flux for steady-state infiltration. Water can flow across the phreatic line, as indicated by the nodal flow rate vectors. Water flow across the phreatic line into the unsaturated zone indicates that the phreatic line is not the uppermost flow line, as assumed in the flownet technique (Fredlund and Rahardjo 1993).

Fattah et al. (2017) found that the water flux decreases linearly with time and with the water level in the reservoir which indicates that the rate of flow in the whole body of the dam shows almost uniform change.

\section{Conclusions}

Based on the experimental results obtained from this research work and analysis of the behavior of a zoned earth dam with unsaturated zone, the seepage and flow analysis carried out on Al-Adhaim dam using the finite element method, the following conclusions can be drawn:

1) The procedure of analysis of the seepage of earth dam including zone of unsaturated soil required a proposed procedure to define the (hydraulic conductivity-suction function. It depends on predicting the SWCC by applying fitting methods with the aid of the program SoilVision, after identifying the basic properties of the soil such as Attereberg limits, particle size distribution, void ratio, porosity, and wet and dry unit weights. The slope of the latter relation can be used to define the $\mathrm{k}_{\text {unsat }}$ - function. The procedure is found to be successful.

2) The three conditions of water level in the reservoir $143.5 \mathrm{~m}, 131.5 \mathrm{~m}$ and $115.75 \mathrm{~m}$ showed that the exit gradient is always less than 1.0 for each degree of saturation. The exit gradient is increased by about $89 \%$ and $218 \%$ when the water level is raised to $131.5 \mathrm{~m}$ and $143.5 \mathrm{~m}$, respectively. This is attributed to increased water head. At the same time, the rate of flow is increased by about $89 \%$ and $218 \%$. This means that the increase in rate of flow is approximately equal to the increase of exit gradient due to rising of water level in the reservoir.

3) The rate of flow is decreased by about $20-27 \%$ when the degree of saturation of the core material is decreased from $100 \%$ to $50 \%$ at water level 115.75 $\mathrm{m}$, while the exit gradient of flow is decreased by about $13-15 \%$. This decrease in flow rate becomes $13-15 \%$ and $8-9.5 \%$ when the reservoir water level is $131.5 \mathrm{~m}$ and $143.5 \mathrm{~m}$, respectively, while the exit gradient of flow is increased by about $23-29.5 \%$ and $29-29.5 \%$ when the reservoir water level is $131.5 \mathrm{~m}$ and $143.5 \mathrm{~m}$, respectively.

4) When the state of soil changes from fully saturated $\mathrm{S}=100 \%$ to partially saturated, a rapid increase in head gradient and pore water takes place at the embankment base for different water levels in the reservoir. This decrease plateaus out on further degrease in $\mathrm{S}$.

Table 1. Index properties of the soil.

\begin{tabular}{|l|c|}
\hline \multicolumn{1}{|c|}{ Index property } & Value \\
\hline Liquid limit \%, LL & 50 \\
\hline Plasticity index \%, PI & 25 \\
\hline Specific gravity, Gs & 2.79 \\
\hline Sand \% & 3.3 \\
\hline Silt \% & 31.7 \\
\hline Clay\% & 65 \\
\hline Classification USCS & CL \\
\hline Optimum moisture content & $13.75 \%$ \\
\hline $\begin{array}{l}\text { Maximum dry unit weight } \\
\text { kN/m }\end{array}$ & 17.13 \\
\hline
\end{tabular}

Table 2: The permeability of Al-Adhaim's dam materials (Al-Adhaim Dam Report, 1994).

\begin{tabular}{|c|c|c|c|}
\hline \multirow{2}{*}{ Type of material } & \multicolumn{2}{c|}{ Coefficient of permeability $(\mathrm{m} / \mathrm{sec})$} \\
\cline { 2 - 4 } & Horizontal $k_{\mathrm{h}}$ & Vertical $k_{\mathrm{v}}$ \\
\hline \multicolumn{2}{|c|}{ The shell } & $1.25 \times 10^{-5}$ & $1.25 \times 10^{-5}$ \\
\hline \multicolumn{2}{|c|}{ The core } & $2.25 \times 10^{-7}$ & $1.0 \times 10^{-7}$ \\
\hline \multirow{2}{*}{$\begin{array}{c}\text { The } \\
\text { filters }\end{array}$} & Filter F & $1.2 \times 10^{-3}$ & $1.2 \times 10^{-3}$ \\
\cline { 2 - 4 } & Filter T & $1 \times 10^{-2}$ & $1 \times 10^{-2}$ \\
\hline \multirow{2}{*}{$\begin{array}{c}\text { The } \\
\text { found- } \\
\text { ation }\end{array}$} & Marl & $1 \times 10^{-10}$ & $1 \times 10^{-10}$ \\
\cline { 2 - 4 } & Sandstone & $5.5 \times 10^{-6}$ & $5.5 \times 10^{-6}$ \\
\hline
\end{tabular}

Table 3: Material properties for the assumed core soil.

\begin{tabular}{|c|c|c|}
\hline Parameter & Value & Unit \\
\hline Total unit weight, $\gamma_{\mathrm{t}}$ & 21.017 & $\mathrm{kN} / \mathrm{m}^{3}$ \\
\hline Dry unit weight, $\gamma_{\mathrm{d}}$ & 17.13 & $\mathrm{kN} / \mathrm{m}^{3}$ \\
\hline Porosity $\mathrm{n}, \%$ & 38.65 & Degree \\
\hline Void ratio e & 0.63 & - \\
\hline $\begin{array}{c}\text { Saturated hydraulic } \\
\text { conductivity, } k\end{array}$ & $1.097 \times 10^{-7}$ & $\mathrm{~m} / \mathrm{sec}$ \\
\hline
\end{tabular}


Table 4: Results of the basic analysis.

\begin{tabular}{|l|c|c|c|}
\hline \multicolumn{4}{|c|}{ The original soil of dam core } \\
\hline & \multicolumn{3}{|c|}{ Height of water $(\mathrm{m})$} \\
\cline { 2 - 4 } & 115.75 & 131.5 & 143.5 \\
\hline Seepage $\times 10^{-5} \mathrm{~m}^{3} / \mathrm{sec} / \mathrm{m}$ & 2.3893 & 4.5125 & 7.5975 \\
\hline Exit gradient & 0.11054 & 0.20877 & 0.3515 \\
\hline Max. velocity $\times 10^{-5} \mathrm{~m} / \mathrm{sec}$ & 0.77028 & 1.4627 & 2.4835 \\
\hline
\end{tabular}

Table 5: Results of the basic analysis.

\begin{tabular}{|l|c|c|c|}
\hline \multicolumn{4}{|c|}{ Selected soil } \\
\hline & \multicolumn{3}{|c|}{ Height of water (m) } \\
\cline { 2 - 4 } & 115.75 & 131.5 & 143.5 \\
\hline $\begin{array}{l}\text { Seepage } \times 10^{-} \\
5\end{array} \mathrm{~m}^{3} /$ day/m & 4.509897 & 7.454249 & 10.35120 \\
\hline Exit gradient & 0.15169 & 0.29172 & 0.48148 \\
\hline $\begin{array}{l}\text { Max. velocity } \\
\mathrm{x} 10^{-5} \mathrm{~m} / \mathrm{sec}\end{array}$ & 0.69136 & 1.3396 & 2.12017 \\
\hline
\end{tabular}

Table 6: Summary of pore water pressure and head gradient at nodes $\mathrm{A}$ and $\mathrm{B}$ predicted at different degrees of saturation.

\begin{tabular}{|c|c|c|}
\hline \multicolumn{3}{|c|}{ a. Height of water $(115.75 \mathrm{~m})$} \\
\hline \multirow[t]{2}{*}{ Degree of saturation $\%$} & \multicolumn{2}{|c|}{ Pore water pressure $(\mathrm{kPa})$} \\
\hline & Node A & Node B \\
\hline 40 & 192.8 & 396.9 \\
\hline 50 & 191.8 & 397.23 \\
\hline 60 & 193.68 & 398.91 \\
\hline$\overline{70}$ & 194.35 & 398.95 \\
\hline 80 & 194.03 & 406.83 \\
\hline 90 & 194.24 & 398.94 \\
\hline 100 & 178.85 & 394.57 \\
\hline \multicolumn{3}{|c|}{ b. Height of water $(131.5 \mathrm{~m})$} \\
\hline \multirow[t]{2}{*}{ Degree of saturation $\%$} & \multicolumn{2}{|c|}{ Pore water pressure $(\mathrm{kPa})$} \\
\hline & Node A & Node B \\
\hline 40 & 321.12 & 528.05 \\
\hline 50 & 314.92 & 5.2771 \\
\hline 60 & 318.31 & 528.09 \\
\hline 70 & 319.01 & 528.19 \\
\hline 80 & 317.31 & 527.5 \\
\hline 90 & 319.46 & 528.14 \\
\hline 100 & 320.54 & 527.52 \\
\hline \multicolumn{3}{|c|}{ c. Height of water $(143.5 \mathrm{~m})$} \\
\hline \multirow[t]{2}{*}{ Degree of saturation $\%$} & \multicolumn{2}{|c|}{ Pore water pressure $(\mathrm{kPa})$} \\
\hline & Node A & Node B \\
\hline 40 & 421.15 & 633.14 \\
\hline 50 & 418.40 & 629.79 \\
\hline 60 & 421.22 & 630.20 \\
\hline 70 & 422 & 630.29 \\
\hline 80 & 422.25 & 630.35 \\
\hline 90 & 422.51 & 630.28 \\
\hline 100 & 313.29 & 632.40 \\
\hline
\end{tabular}

Table 7: Summary of head gradient at nodes A and B predicted at different degrees of saturation.

\begin{tabular}{|c|c|c|}
\hline \multicolumn{3}{|c|}{ Height of water (115.75m) } \\
\hline \multirow[t]{2}{*}{ Degree of saturation } & \multicolumn{2}{|c|}{ Head gradient } \\
\hline & Node A & Node B \\
\hline 40 & 0.44189 & 0.2677 \\
\hline 50 & 0.46981 & 0.27364 \\
\hline 60 & 0.46291 & 0.27281 \\
\hline 70 & 0.45692 & 0.27231 \\
\hline 80 & 0.45660 & 0.27162 \\
\hline 90 & 0.45585 & 0.27207 \\
\hline 100 & 0.66071 & 0.92253 \\
\hline \multicolumn{3}{|c|}{ Height of water (131.5m) } \\
\hline \multirow[t]{2}{*}{ Degree of saturation $\%$} & \multicolumn{2}{|c|}{ Head gradient } \\
\hline & Node A & Node B \\
\hline 40 & 0.92681 & 0.48022 \\
\hline 50 & 0.94768 & 0.48224 \\
\hline 60 & 0.92487 & 0.47991 \\
\hline 70 & 0.92060 & 0.47933 \\
\hline 80 & 0.91781 & 0.47836 \\
\hline 90 & 0.91842 & 0.47970 \\
\hline 100 & 1.1062 & 1.59556 \\
\hline \multicolumn{3}{|c|}{ Height of water (143.5m) } \\
\hline \multirow[t]{2}{*}{ Degree of saturation $\%$} & \multicolumn{2}{|c|}{ Head gradient } \\
\hline & Node A & Node B \\
\hline 40 & 1.1412 & 0.58895 \\
\hline 50 & 1.1598 & 0.59099 \\
\hline 60 & 1.1404 & 0.5885 \\
\hline 70 & 1.1356 & 0.58812 \\
\hline 80 & 1.1340 & 0.58780 \\
\hline 90 & 1.1331 & 0.58830 \\
\hline 100 & 1.5506 & 1.9252 \\
\hline
\end{tabular}


Table 8: Results of rate of flow, exit gradient and velocity in the earth dam at different degrees of saturation.

\begin{tabular}{|c|c|c|c|}
\hline & \multicolumn{3}{|c|}{ a. Degree of saturation $=40 \%$} \\
\hline & \multicolumn{3}{|c|}{ Height of water (m) } \\
\hline & 115.75 & 131.5 & 143.5 \\
\hline Seepage $\left(\times 10^{-5} \mathrm{~m}^{3} / \mathrm{sec} / \mathrm{m}\right)$ & 3.584909 & 6.565795 & 9.537696 \\
\hline Exit gradient & 0.13123 & 0.23181 & 0.37242 \\
\hline \multirow{4}{*}{$\begin{array}{r}\text { Max. Velocity }\left(\times 10^{-5} \mathrm{~m} / \mathrm{sec}\right) \\
\mathrm{b}\end{array}$} & 0.59728 & 1.10814 & 2.0228 \\
\hline & \multicolumn{3}{|c|}{ b. $\quad$ Degree of saturation $=50 \%$} \\
\hline & \multicolumn{3}{|c|}{ Height of water (m) } \\
\hline & 115.75 & 115.75 & 115.75 \\
\hline Seepage $\left(\times 10^{-5} \mathrm{~m}^{3} / \mathrm{sec} / \mathrm{m}\right)$ & 3.563482 & 6.5232 & 9.492768 \\
\hline Exit gradient & 0.13094 & 0.23109 & 0.37165 \\
\hline Max. Velocity $\left(\mathrm{x} 10^{-5} \mathrm{~m} / \mathrm{sec}\right)$ & 0.56332 & 1.1253 & 2.0353 \\
\hline \multicolumn{4}{|c|}{ c. $\quad$ Degree of saturation $=60 \%$} \\
\hline & \multicolumn{3}{|c|}{ Height of water (m) } \\
\hline & 115.75 & 115.75 & 115.75 \\
\hline Seepage $\left(\times 10^{-5} \mathrm{~m}^{3} / \mathrm{sec} / \mathrm{m}\right)$ & 3.626726 & 6.571411 & 9.545472 \\
\hline Exit gradient & 0.13194 & 0.23191 & 0.37255 \\
\hline Max. Velocity $\left(\mathrm{x} 10^{-5} \mathrm{~m} / \mathrm{sec}\right)$ & 0.55373 & 1.1063 & 2.0199 \\
\hline \multicolumn{4}{|c|}{ d. $\quad$ Degree of saturation $=70 \%$} \\
\hline & \multicolumn{3}{|c|}{ Height of water (m) } \\
\hline & 115.75 & 115.75 & 115.75 \\
\hline Seepage $\left(\times 10^{-5} \mathrm{~m}^{3} / \mathrm{sec} / \mathrm{m}\right)$ & 3.632947 & 6.582989 & 9.558432 \\
\hline Exit gradient & 0.13205 & 0.23211 & 0.37274 \\
\hline Max. Velocity $\left(\mathrm{x} 10^{-5} \mathrm{~m} / \mathrm{sec}\right)$ & 0.55115 & 1.1026 & 2.0162 \\
\hline \multicolumn{4}{|c|}{ e. $\quad$ Degree of saturation $=80 \%$} \\
\hline & \multicolumn{3}{|c|}{ Height of water (m) } \\
\hline & 115.75 & 115.75 & 115.75 \\
\hline Seepage $\left(\times 10^{-5} \mathrm{~m}^{3} / \mathrm{sec} / \mathrm{m}\right)$ & 3.665261 & 6.514646 & 9.559296 \\
\hline Exit gradient & 0.13242 & 0.23219 & 0.37285 \\
\hline \multirow{4}{*}{ Max. Velocity $\left(\times 10^{-5} \mathrm{~m} / \mathrm{sec}\right)$} & 0.55102 & 1.1022 & 2.0158 \\
\hline & aturation $=$ & & \\
\hline & \multicolumn{3}{|c|}{ Height of water (m) } \\
\hline & 115.75 & 131.5 & 143.5 \\
\hline Seepage $\left(\times 10^{-5} \mathrm{~m}^{3} / \mathrm{sec} / \mathrm{m}\right)$ & 3.659299 & 6.476371 & 9.56448 \\
\hline Exit gradient & 0.13319 & 0.232 & 0.37277 \\
\hline Max. Velocity $\left(\mathrm{x} 10^{-5} \mathrm{~m} / \mathrm{sec}\right)$ & 0.55102 & 1.1022 & 2.0158 \\
\hline
\end{tabular}




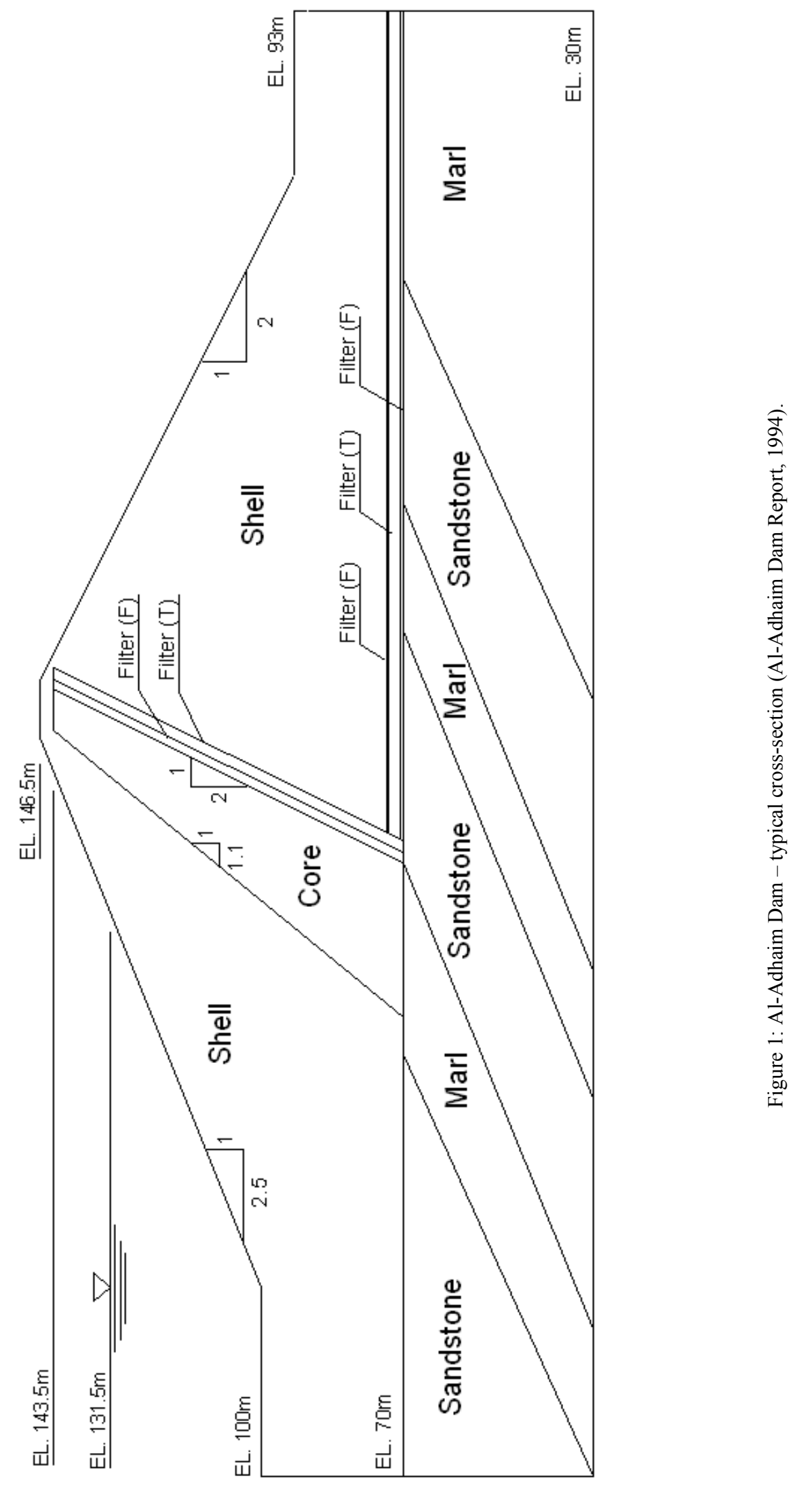




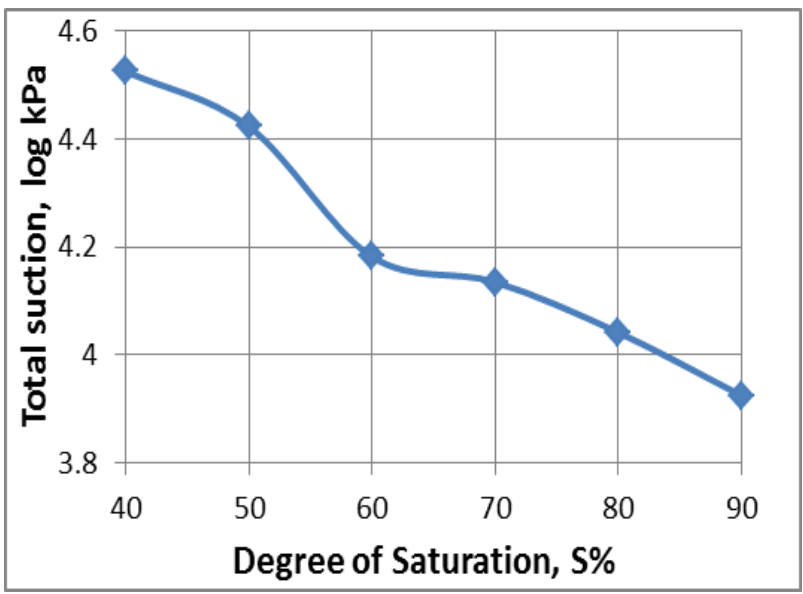

Figure 2: Relationship between the total suction and degree of saturation.

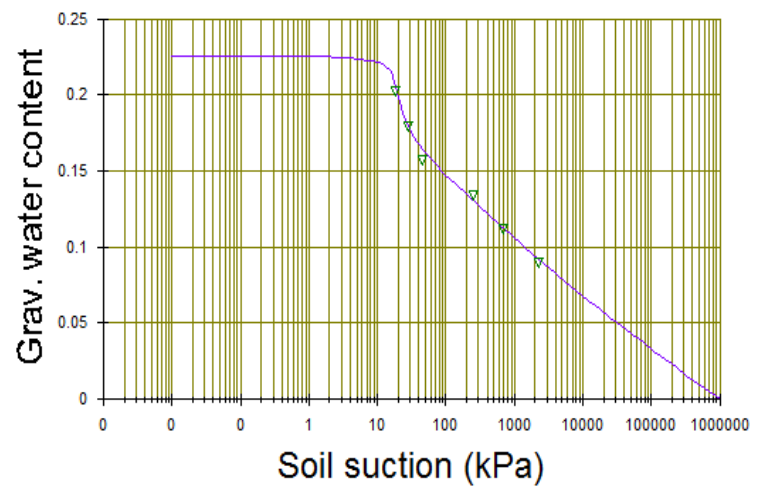

(a) Using Fredlund and Xing (1994) fitting.

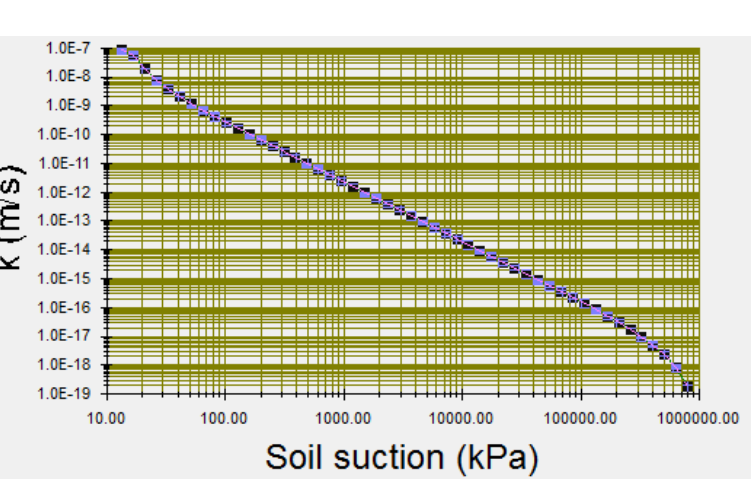

a. hydraulic conductivity at $\mathrm{S}=90 \%$.

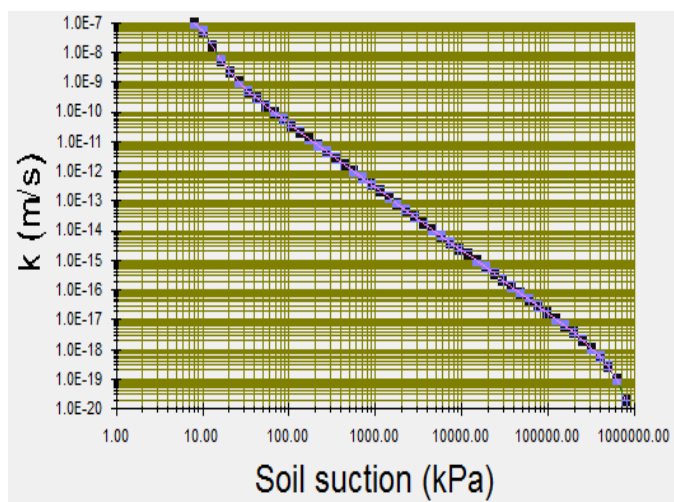

C-hydraulic conductivity at $\mathrm{S}=70 \%$.

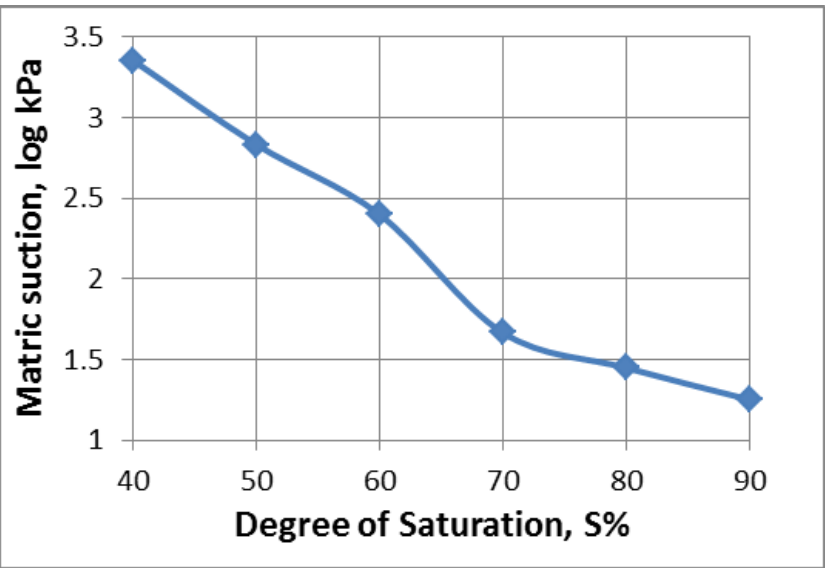

Figure 3: Relationship between the matric suction and degree of saturation.

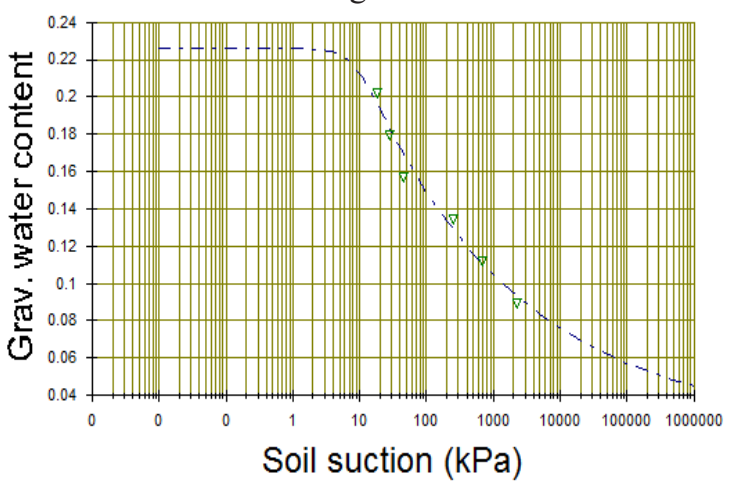

(b) Using Van Genuchten (1980) fitting.

er content and the matric suction obtained by the program Soil Vision

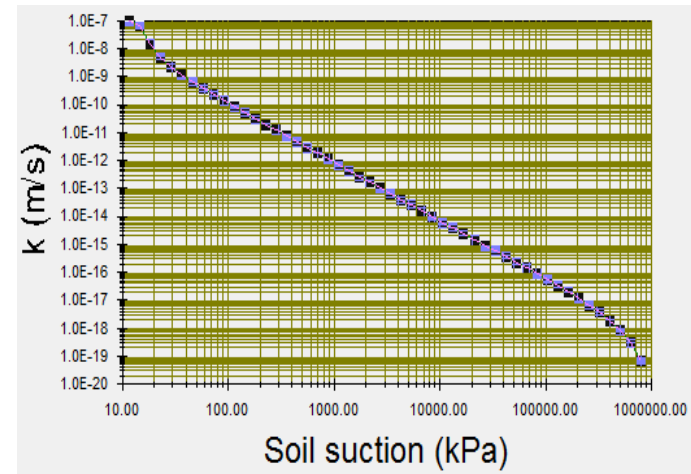

b.hydraulic conductivity at $\mathrm{S}=80 \%$.

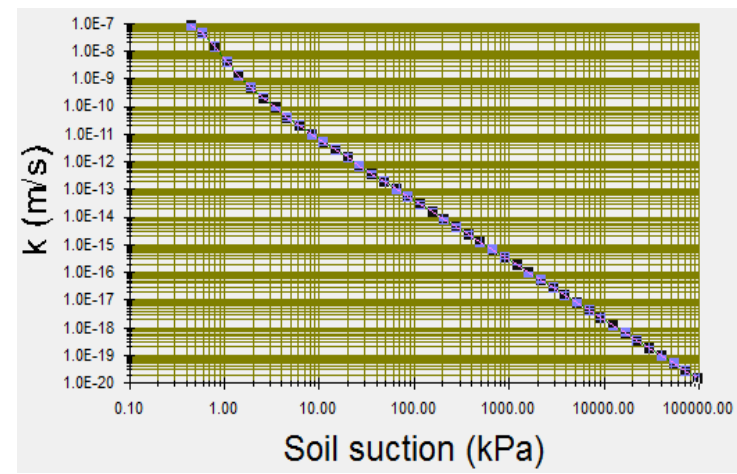

D-hydraulic conductivity at $\mathrm{S}=40 \%$.

Figure 5: Relationships between the hydraulic conductivity and the matric suction for different degrees of saturation obtained by the program Soil Vision. 


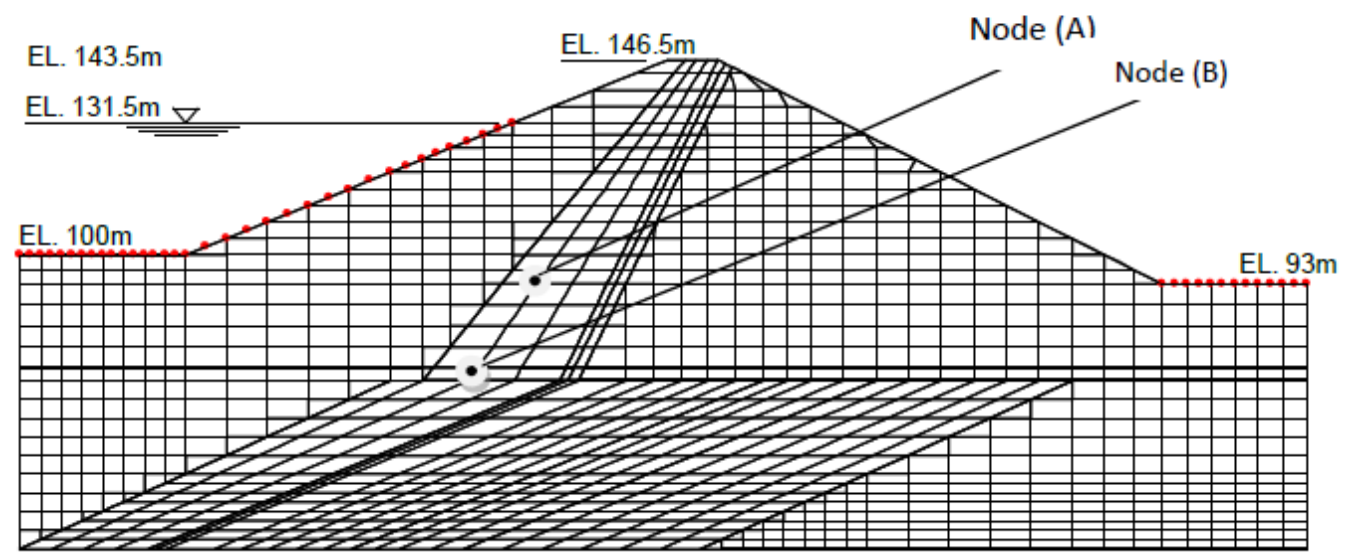

Figure 6: Typical finite element mesh for Al-Adhaim Dam.

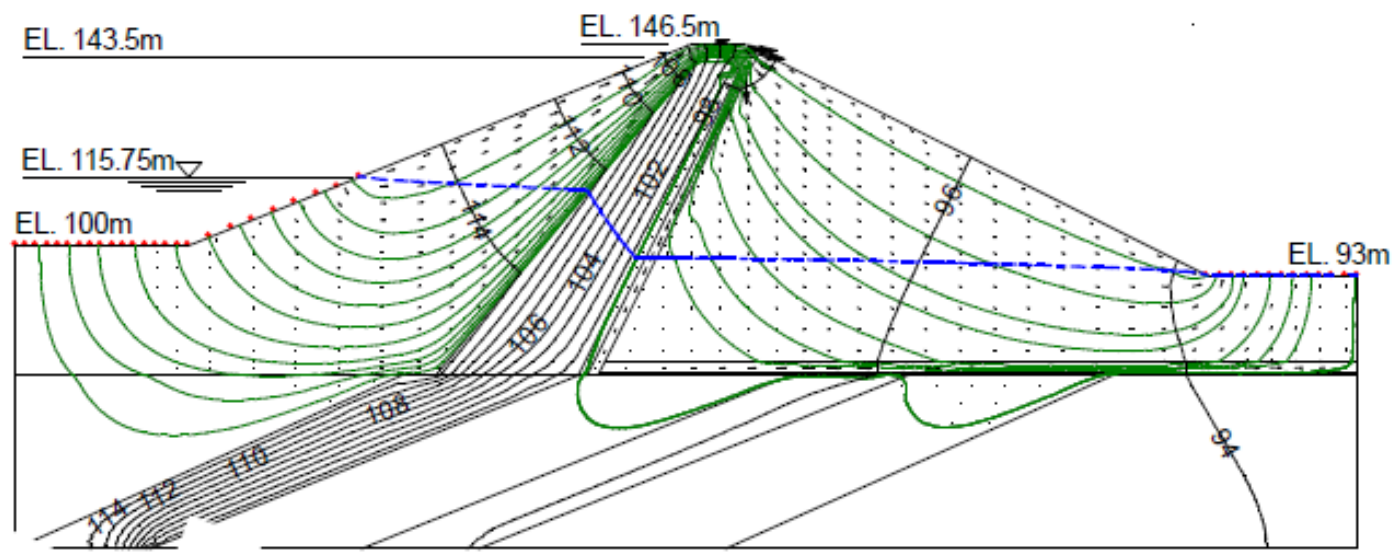

Figure 7: Contours of the total head (in meters) and flow path when the earth dam is without filters and the head of water is $115.75 \mathrm{~m}$.

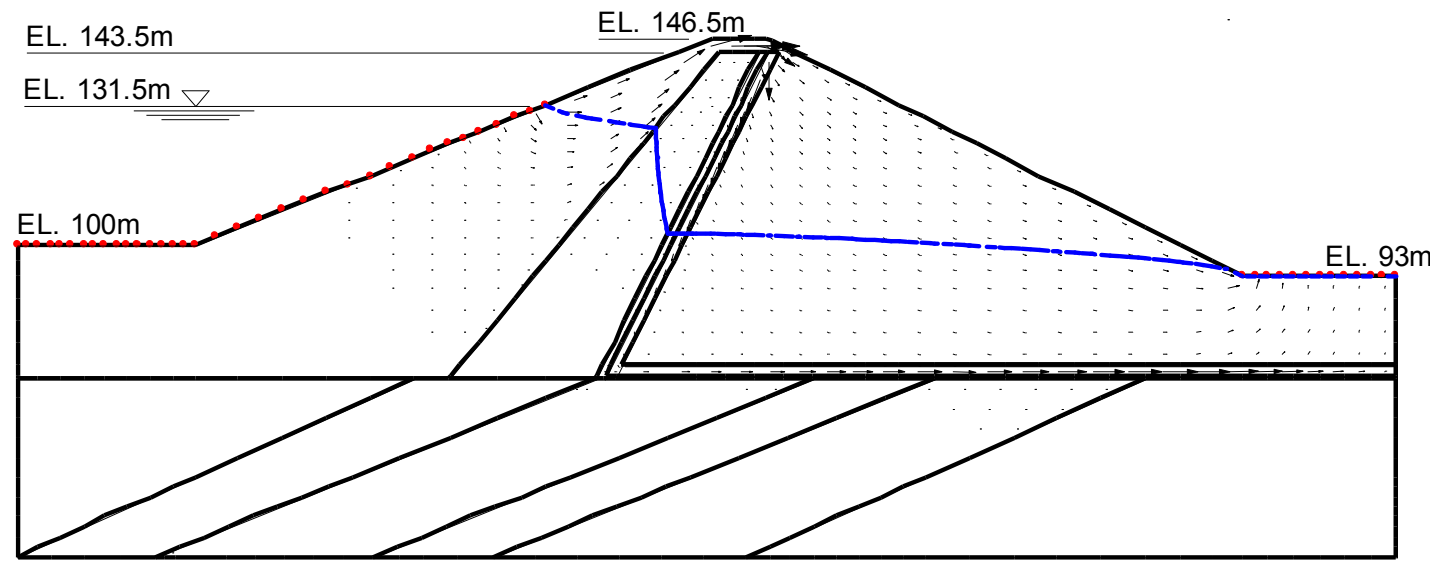

Figure 8: The seepage line and the velocity vectors for Al-Adhaim dam when the head of water is $115.75 \mathrm{~m}, \mathrm{~S}=100 \%$, dam with filters. 


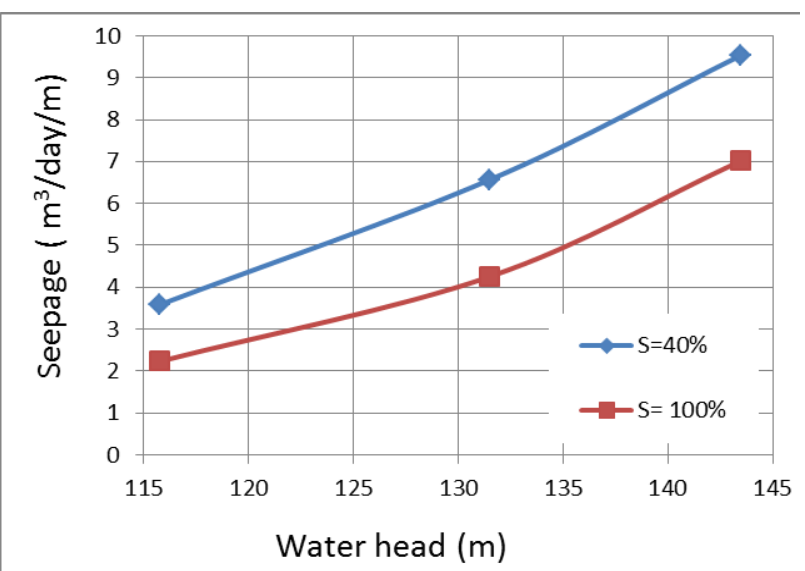

Figure 9: Relationship between the quantity of seepage and head of water of the earth dam without filters, for degree of saturation $\mathrm{S}=40 \%$ and $100 \%$.

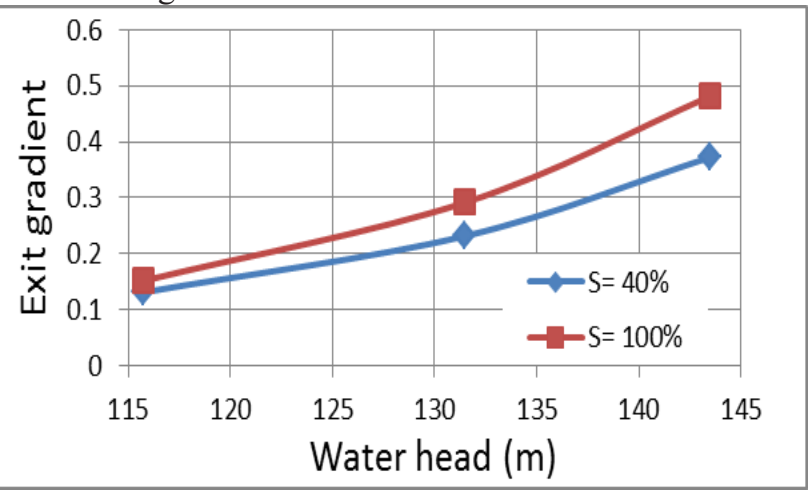

Figure 11: Relationship between the exit gradient and head of water of the earth dam without filters for degree of saturation $\mathrm{S}=40 \%$ and $100 \%$.

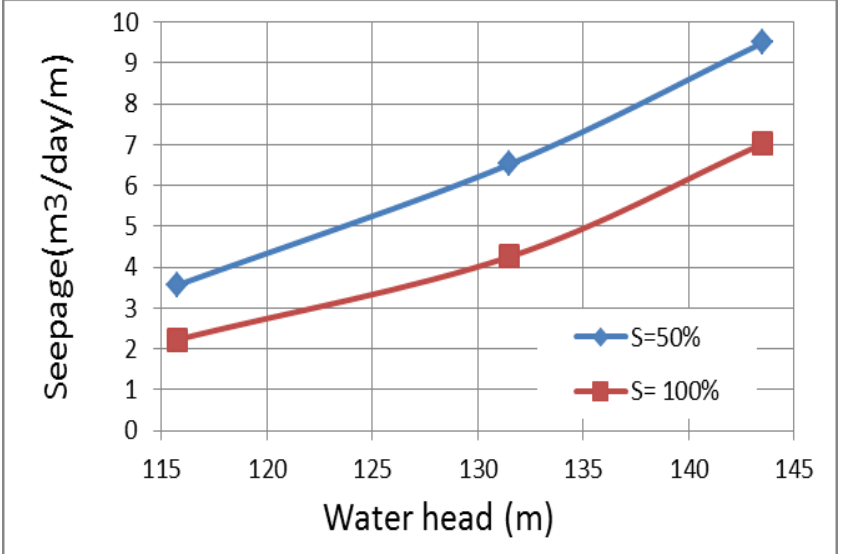

Figure 10: Relationship between the quantity of seepage and head of water of the earth dam without filters, for degree of saturation $\mathrm{S}=50 \%$ and $100 \%$.

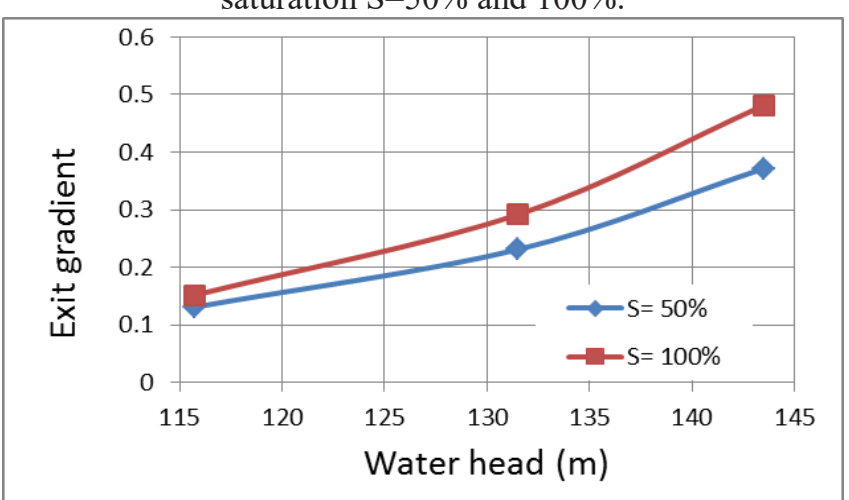

Figure 12: Relationship between the exit gradient and head of water of the earth dam without filters for degree of saturation $\mathrm{S}=50 \%$ and $100 \%$.

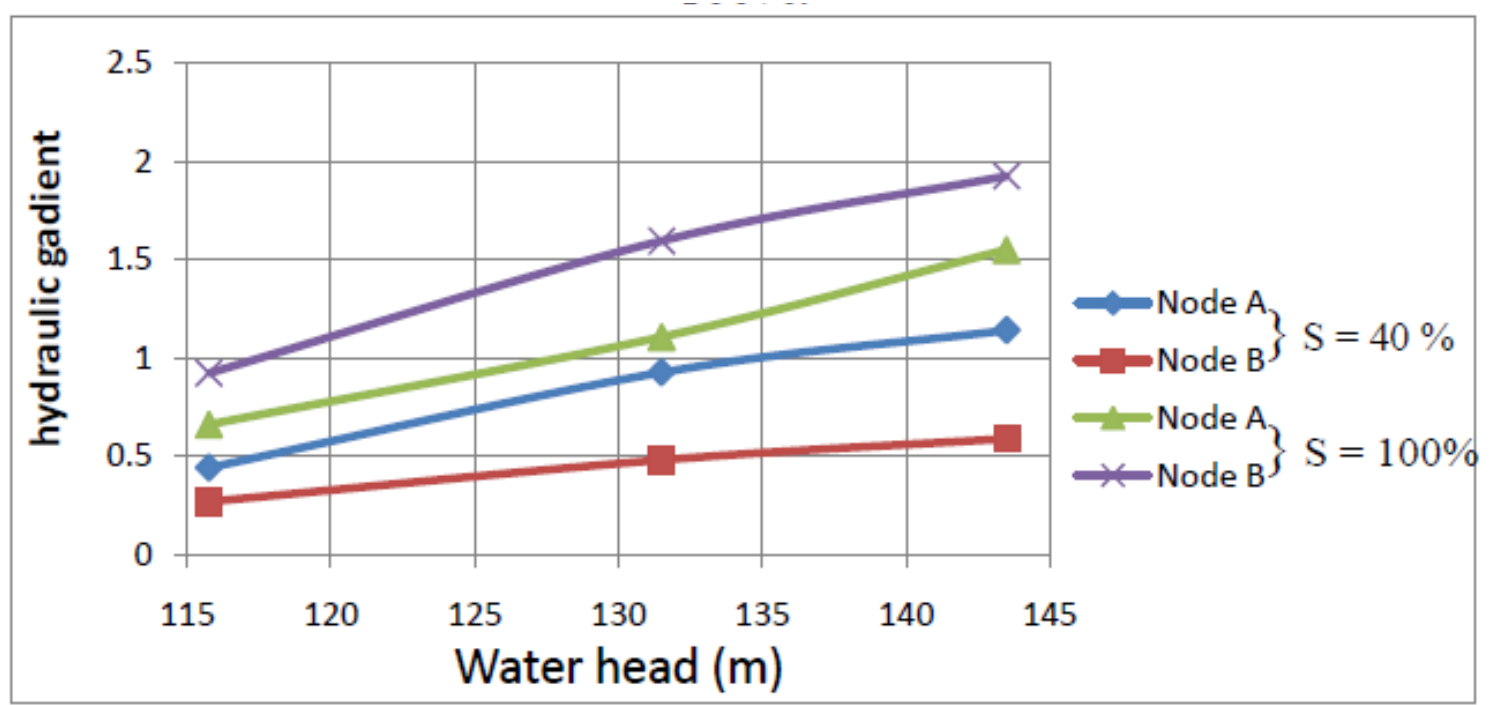

Figure 13: Relationship between the head gradient and head of water of the earth dam at nodes A and B without filters, for degree of saturation $S=40 \%$ and $100 \%$ 


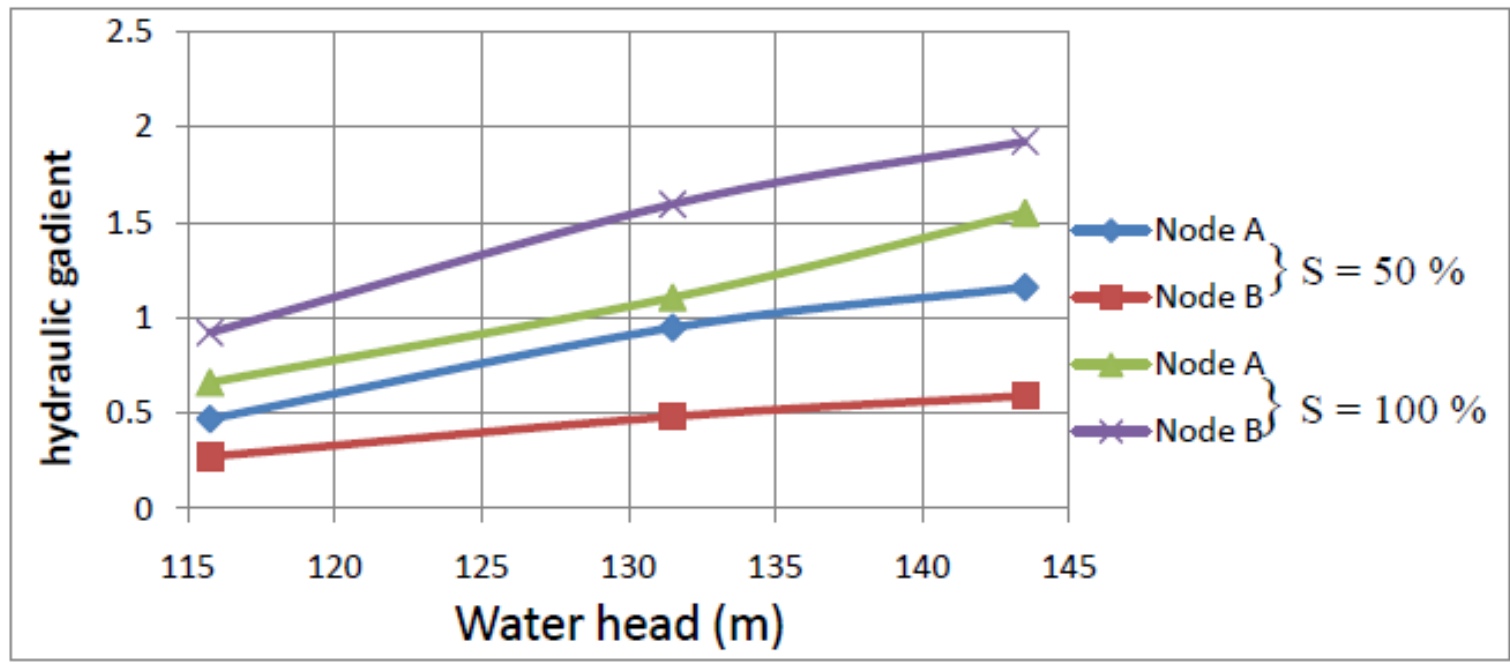

Figure 14: Relationship between the head gradient and the head of water of earth dam at nodes A and B without filters, for degree of saturation $\mathrm{S}=50 \%$ and $100 \%$.



Figure 15: Relationship between the pore water pressure and the head of water of the earth dam at node A and B without filters, for degree of saturation $\mathrm{S}=40 \%$ and $100 \%$.

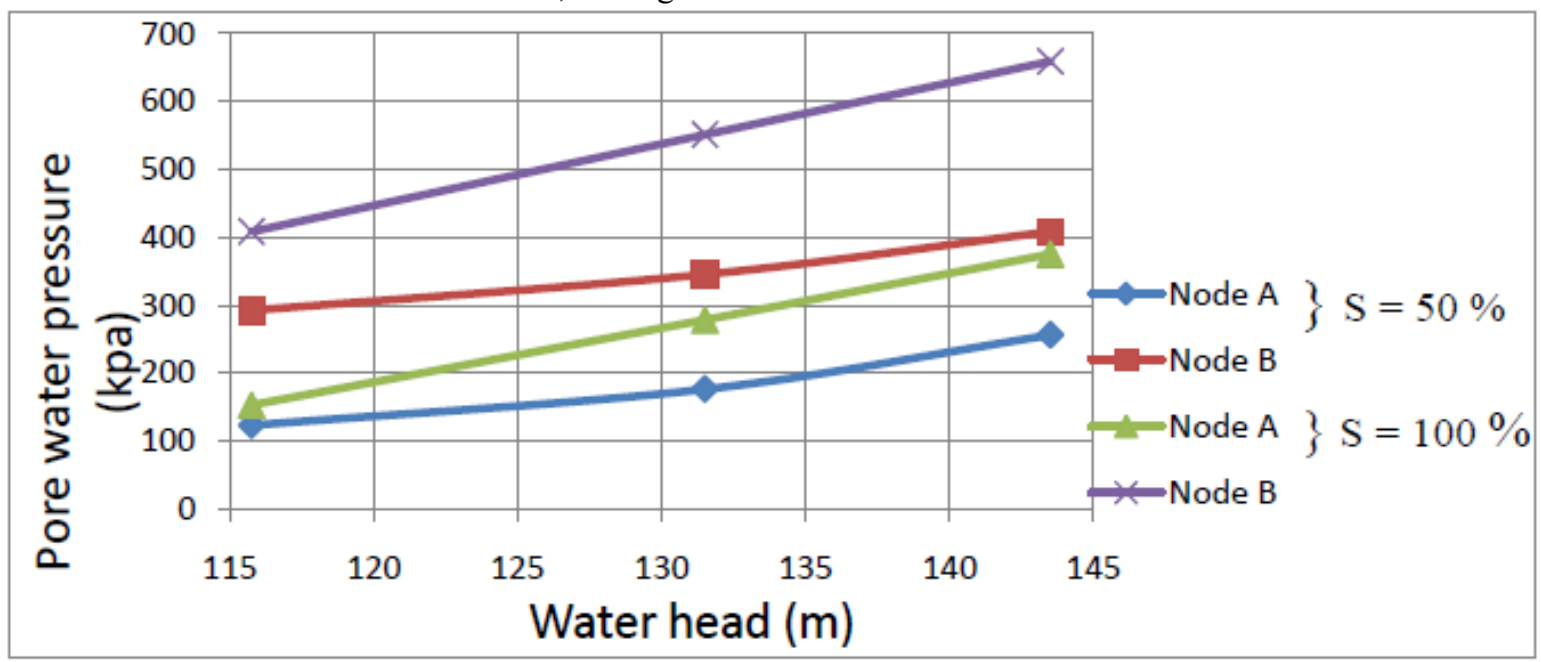

Figure 16: Relationship between the pore water pressure and head of water of the earth dam at node A and B without filters, for degree of saturation $\mathrm{S}=50 \%$ and $100 \%$. 


\section{References}

1. Al-Adhaim Dam Report, Final Report of Al-Adhaim Earth Dam, Unpublished Report, Engineering Consultancy Bureau, University of Baghdad, Iraq, (1994).

2. ASTM-D422-00, Annual Book of ASTM Standards, 04.08, Soil and Rock, pp. $1-8$.

3. ASTM-D698-00, Annual Book of ASTM Standards, 04.08, Soil and Rock, pp. $1-11$.

4. ASTM-D854-00, Annual Book of ASTM Standards, 04.08, Soil and Rock, pp. $1-7$.

5. ASTM-D4318-00, Annual Book of ASTM Standards, 04.08, Soil and Rock, pp. $1-16$.

6. ASTM-D-5298-03, Annual Book of ASTM Standards, 04.08, Soil and Rock, pp. $1-6$.

7. Bouchemella, S., Seridi, A., Alimi-Ichola, I., European Journal of Environmental and Civil Engineering, Vol. 18, June, DOI: 10.1080/19648189.2014.926294, Taylor and Francis, (2014).

8. Fattah, M. Y., Omran, H. A., Hassan, M. A., Acta Montanistica Slovaca, 22, 1, pp. 43-57, (2017).

9. Fredlund, D.G., Rahardjo, H., Soil Mechanics for Unsaturated Soils, John Wiley \& Sone Inc. New York, United States of America, (1993).

10. Fredlund, D.G., Xing, A., Canadian Geotechnical Journal Vol. 31, No. 4, pp. 521 - 532, DOI, 10.1139/t94-060, (1994).

11. Head, K. H., Epps, R. J., 3rd edition, Whittles Publishing, UK, (2011).

12. Ho, P.G., B.Sc. Thesis, University of Saskatchewan, Saskatoon, Canada, (1979).

13. Lam, L., Fredlund, D.G., and Barbour, S.L., Canadian Geotechnical Journal, 24, 4, pp. 565-580, DOI 10.1139/t87-071, (1987).

14. Thieu, N. T. M., Fredlund, M. D., Fredlund, D. G., and $\mathrm{Vu}, \mathrm{H}$. Q., Proc., Int. Conf. on Management of the Land and Water Resources, Hanoi, Vietnam, pp. 49-56, (200).

15. Usre's Guide Manual of Soil Vision, Soil Vision Systems Ltd. Saskatoon, Saskatchewan, Canada, (2001).

16. Van Genuchten, M. T., Soil Science Society America Journal, 44, pp. 892 - 898, (1980). 